\title{
ALGUNAS AGUADAS INÉDITAS DE JOSÉ D. BÉCQUER
}

\author{
por Manuel Piñanes García-Olías
}

Recientemente han aparecido en Sevilla procedentes del mercado de arte británico un importante conjunto de dibujos a la aguada del pintor José D. Bécquer (1805-1841), padre de los famosos Gustavo Adolfo y Valeriano Bécquer. Esta interesante serie, junto con otras dos aguadas que forman una pareja, conservadas en una colección particular sevillana, nos permiten conocer un poco mejor la obra de este pintor que, aunque debió de ser muy abundante, actualmente es extremadamente rara de encontrar.

José D. Bécquer realizó numerosas aguadas, tanto de tipos castizos como de escenas populares andaluzas. Estas obras, tratadas con indudable gracia y espontaneidad, eran muy estimadas tanto por los aficionados españoles ${ }^{1}$ como por los viajeros extranjeros de paso por Sevilla durante los años 30 del pasado siglo. Estos viajeros eran, sobre todo, ingleses, y entre ellos Bécquer tenía una importante clientela ${ }^{2}$, hasta el punto que nuestro pintor exportaba sus cuadros desde

1. El pintor Jenaro Pérez Villaamil estuvo en Sevilla en octubre de 1833. Es posible que adquiriese entonces los dibujos de José D. Bécquer que luego incluiría en su importante obra "La España Artística y Monumental", aparecida entre 1842 y 1844. Las láminas dibujadas por Bécquer se titulan "El viático en Sevilla", "Los ladrones en una venta", "La Feria de Mairena", "Un baile de gitanos" y "La misa". En todas las láminas, salvo en la última, consta que Bécquer dibujó y Villaamil dirigió. Los dibujos originales de las dos últimas litografías pertenecían a D. Félix Boix en 1913, y se mostraron en la "Exposición de Pinturas Españolas de la primera mitad del Siglo XIX", organizada por la Sociedad de Amigos del Arte (Catálogo n.o 24 y n. ${ }^{\text {a }}$ 25). Vid. GUERRERO LOVILLO, J.: "Los pintores románticos sevillanos". A.H., Tomo XI, 1949, págs. 51 y 52.

2. Sobre todo, le unió una estrecha amistad con Richard Ford, el erudito autor del Handbook for Spain (1845), al que retrató en dibujos a la aguada precisamente ataviado con trajes populares andaluces. Vid. FORD, B.: "Richard Ford en España”. Madrid 1963, págs. 15 y 16. También pintó un retrato del Viceconsul inglés en Sevilla, Julián Williams, que se conserva en una colección particular 
Cádiz, donde tenía un corresponsal, con destino a Inglaterra. Esto explicaría, por un lado, la procedencia de este conjunto de aguadas y, por otro, la escasez de las obras de José Bécquer conservadas en España.

Todas las acuarelas que estudiamos muestran tipos castizos representados de forma individual, que presentan claras analogías con aquellos otros realizados en barro por los escultores malagueños de la misma época: "Un valenciano", "Maja tapándose", "Majo tocando la guitarra", "Bandolero con trabuco" y "Una bailaora". Todos los dibujos están firmados y fechados, constando asimismo que fueron pintados en Sevilla. Aunque su estilo y tratamiento es homogéneo, las fechas de ejecución varían de unos a otros. Mientras los dos primeros están datados en 1833, y el majo tocando la guitarra lo está en el año siguiente, la bailaora, en cambio, tiene la fecha de $1841^{3}$. Llama la atención el número que lleva cada una de ellas. Esto quizá pueda explicarse si pensamos que estas acuarelas forman parte de una colección de tipos populares andaluces que el pintor fue reuniendo durante varios años con vistas a algún proyecto que nosotros actualmente desconocemos, y que podría haber sido, tal vez, una colección de trajes andaluces populares para su publicación en litografías o grabados, como por ejemplo la obra "Colección de Trajes de España... Dispuesta y Grabada por D. Juan de la Cruz" (Madrid, 1777), sobre dibujos del pintor Manuel de la Cruz ${ }^{4}$, y que posiblemente la prematura muerte del artista frustró. Así, el dibujo de la bailaora está fechado en el mismo año de su fallecimiento, 1841, y lleva el número 97. No obstante, cabe también la posibilidad de que estas acuarelas sean parte de un muestrario o repertorio de tipos que el artista utilizaría como modelos y que aprovecharía, conocidas son su facilidad y rapidez en producir, en diferentes composiciones según sus necesidades. Esto último podría explicar que se conserve en una colección particular sevillana una réplica o versión de una de las acuarelas citadas antes, titulada bandolero con trabuco que hace pareja con otra que representa a una maja. La diferencia de calidad y acabado entre estas dos últimas y las anteriormente citadas son notables. El tratamiento de estas últimas

de nuestra ciudad. Por último, añadiremos que el comerciante inglés residente en Cádiz, Frank Hall Standish poseía diez cuadros de José Bécquer que posteriormente donó, junto con toda su colección, al Rey Luis Felipe de Francia.

3. Algunas de estas aguadas debieron salir de España en fecha muy temprana ya que en una de éstas, la que hemos titulado "Maja tapándose", está basada una litografía que aparece en la publicación "The Andalusian Annual" (Londres, 1836) de M.B. Honan. No obstante, hay una diferencia importante: en la aguada original no aparece el escenario romántico que encontramos tras el personaje que en dicha litografía aparece titulado como "La hermosa Rafaela". Vid.: "Iconografía de Sevilla. 1790-1868". Madrid, 1991, pág. 9.

4. Dibujos también realizados a la aguada de colores, que se conservan en el Museo Municipal de Madrid. Vid. Cat. Exp. "Madrid hasta 1875. Testimonios de Historia”. Madrid 1979-1980. págs. 218 y 219. 
es cuidadoso y esmerado. Sobre todo, destaca el cuidado en la representación del escenario de las figuras (en el de la maja una calle de Sevilla, en el del bandolero un paisaje agreste de sierra) que enmarcan perfectamente en su ambiente a los personajes. Otra característica interesante es la terminación de los dibujos en unos contornos redondeados que son exactamente iguales a los que presentan las litografías realizadas sobre dibujos del propio José Bécquer que aparecen en la publicación romántica sevillana "El Álbum sevillano" (1839). En dicha publicación, tres de las doce litografías están realizadas sobre dibujos originales de Bécquer: "Majo de feria", “¿No oye V. que no?" y "Señora con saya y mantilla". Teniendo esto en cuenta, es posible suponer que nuestro pintor ejecutaría varias aguadas y que entre ellas se escogerían las que finalmente serían incluidas en el Álbum. Es evidente que estas dos aguadas a las que nos referimos no fueron elegidas. Sin embargo, sabemos que en el taller litográfico de V.M. Casajús, editor de El Álbum, se litografió algún dibujo más de José Bécquer. Este es el caso de una litografía conservada en el Museo Romántico de Madrid titulada "La cita" 5 , que sin duda, reúne todas las características de las láminas del Álbum, pero que no fue incluida en la edición final. Desconocemos el motivo. Quizá sólo fuera el producto de una prueba. Cabe también la posibilidad de que esta lámina fuese un obsequio a los suscriptores de la obra, a la manera de la "Colección Lithográphica del Rey de España" que añadía, a las 198 estampas previstas, otras seis más como regalo a sus suscriptores.

El Álbum Sevillano es una de las empresas artísticas más interesantes del romanticismo sevillano. Su editor fue el ya mencionado V.M. Casajús, personaje muy relacionado con la mayor parte de los asuntos artísticos y culturales de la ciudad ${ }^{6}$. Sin embargo, la influencia en este proyecto del conocido Barón Taylor es capital. Como es bien sabido, Taylor visitó España entre 1835 y 1837 con el encargo del Rey Luis Felipe de adquirir pinturas de los antiguos maestros españoles con destino a la famosa Galería Española. En esta misión le acompañaban como ayudantes dos pintores franceses, Adrien Dauzats y Pharamond Blanchard. El Barón, durante sus estancias en Sevilla, ayudó y colaboró de manera efectiva en la elaboración del Álbum Sevillano ? . El mismo, era un entusiasta promotor y patrocinador de ambiciosas colecciones de litografías de carácter pintoresco tales como "Voyages pittoresques et romantiques dans l'ancienne France" (1820-

5. Vid. Cat. Exp. "Imagen Romántica de España", Madrid, 1981, n.. 190, pág. 46.

6. V.M. Casajús (1802-1864) dejó constancia de sus importantes cargos culturales en el frontispicio del Álbum: Director del Liceo Artístico y Literario, socio de mérito y facultativo en Bellas Artes de la de Amigos del País, Vicepresidente de su clase de Literatura y Artes, Secretario del Museo Provincial y Director del Establecimiento Litográfico de esta ciudad.

7. El ejemplar del Álbum Sevillano, conservado en la Biblioteca Nacional de Madrid, está dedicado al Barón Taylor por V.M. Casajús: “Al S. Bon., J. Taylor lo ofre. b.s.m. el Editor”. 
1878) y el "Voyage pittoresque en Espagne, en Portugal et sur la côte d'Afrique, de Tanger a Tetouan" (1826-1860). Por otro lado, sus dos ayudantes intervinieron activamente en el Álbum, proporcionando entre los dos la mitad de las escenas pintorescas que aparecen en dicha publicación.

Al hilo de nuestra exposición, consideramos bastante probable que Taylor no sólo conociera a Bécquer, sino que además, adquiriese alguna de sus aguadas, y podemos conjeturar que entre ellas estarían las tres que representan a un torero, primer espada; un torero; y un torero con capa. Conocemos estas obras gracias a que el artista francés Achille Devèria se basó en ellas para realizar unas litografías hacia 1838 , que por su asunto español eran por entonces muy apreciadas por el público francés. Esta suposición la sustentamos en el hecho de que tanto el Barón Taylor como Achille Devèria estaban relacionados con el movimiento romántico francés y con su máximo exponente: Víctor Hugo. No hay que olvidar que Taylor, como Comisario Real del "Théâtre Français", dio entrada en el repertorio de este teatro a una obra tan revolucionaria como "Hernani", del propio Víctor Hugo. Por lo demás, son bien conocidas las relaciones de A. Devèria y de su hermano, el pintor Eugene, con el mismo escritor. Teniendo esto en cuenta, no es descabellado pensar que Taylor, después de su importante misión en España, estuviese dispuesto a proporcionar a Devèria información sobre las costumbres de aquel país, al tiempo que le cedía las aguadas para su reproducción litográfica que por su fidelidad a la realidad, puesto que habían sido hechas por un español, podrían constituir un éxito de venta ${ }^{8}$.

De este modo, quedaría aclarada la vía por la que llegaron a Francia unas escenas taurinas de las que, al menos una, tuvo especial importancia al ser la fuente de inspiración de una obra del gran pintor francés Edouard Manet ${ }^{9}$.

8. Vid. LIPSCHUTZ, I.A.: "La pintura española y los románticos franceses". Madrid, 1988, pág. 134.

9. Se trata del apunte titulado "Joven en traje de torero". Vid. CASO, J. de: "Una fuente de hispanismo de Manet". Goya n. ${ }^{\circ}$ 68, págs. 94-97. 


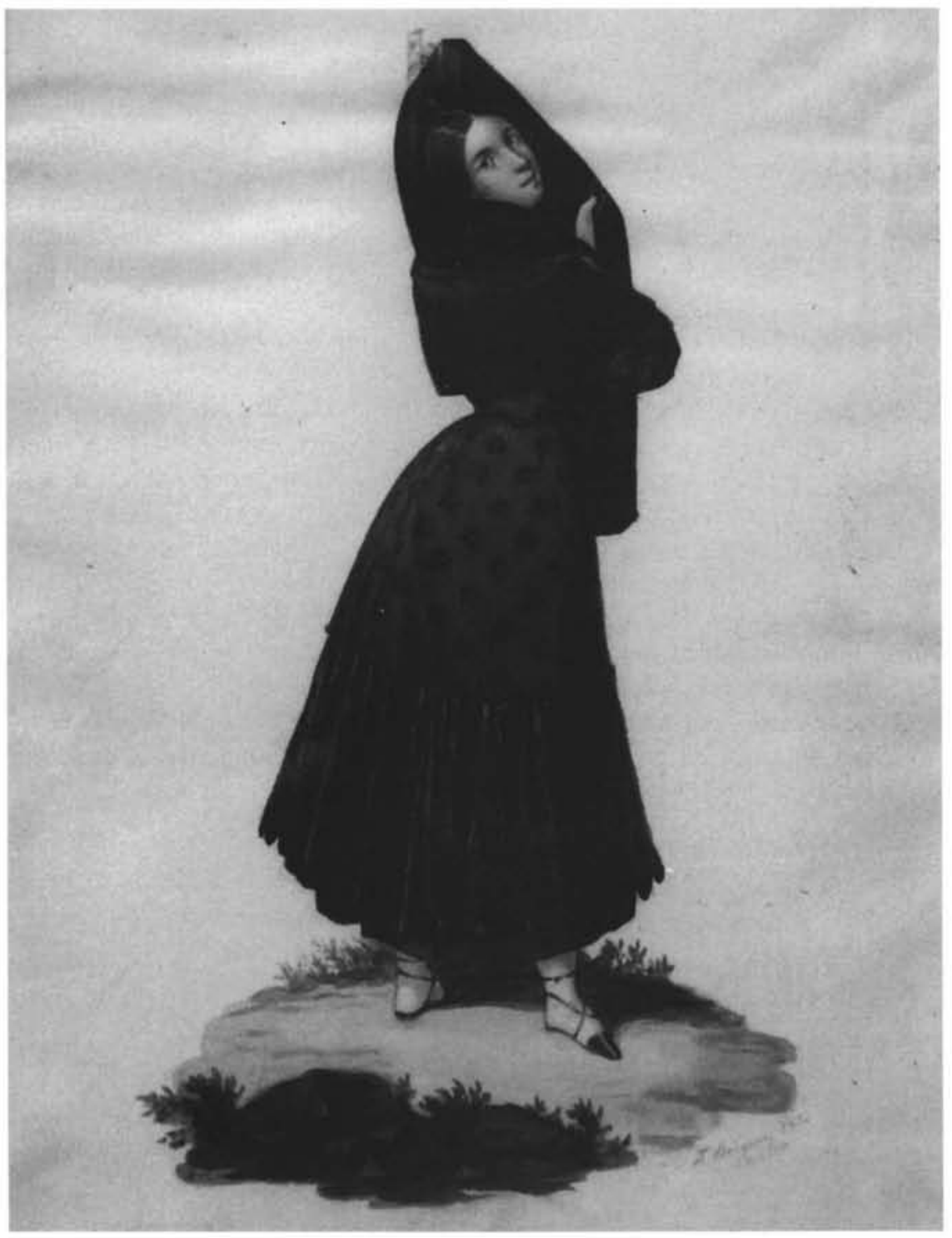

Lám. 1. 


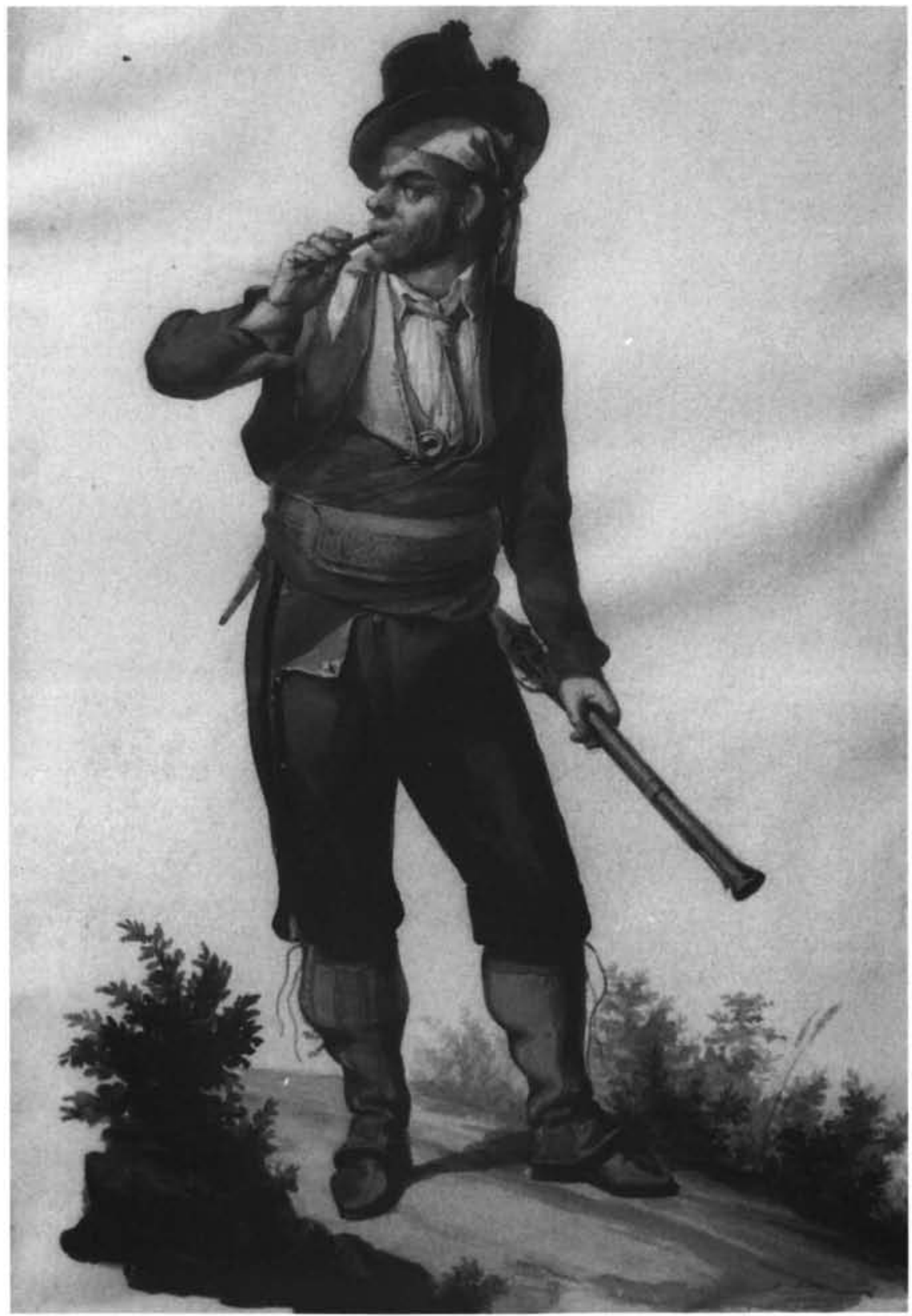

Lám. 2. 


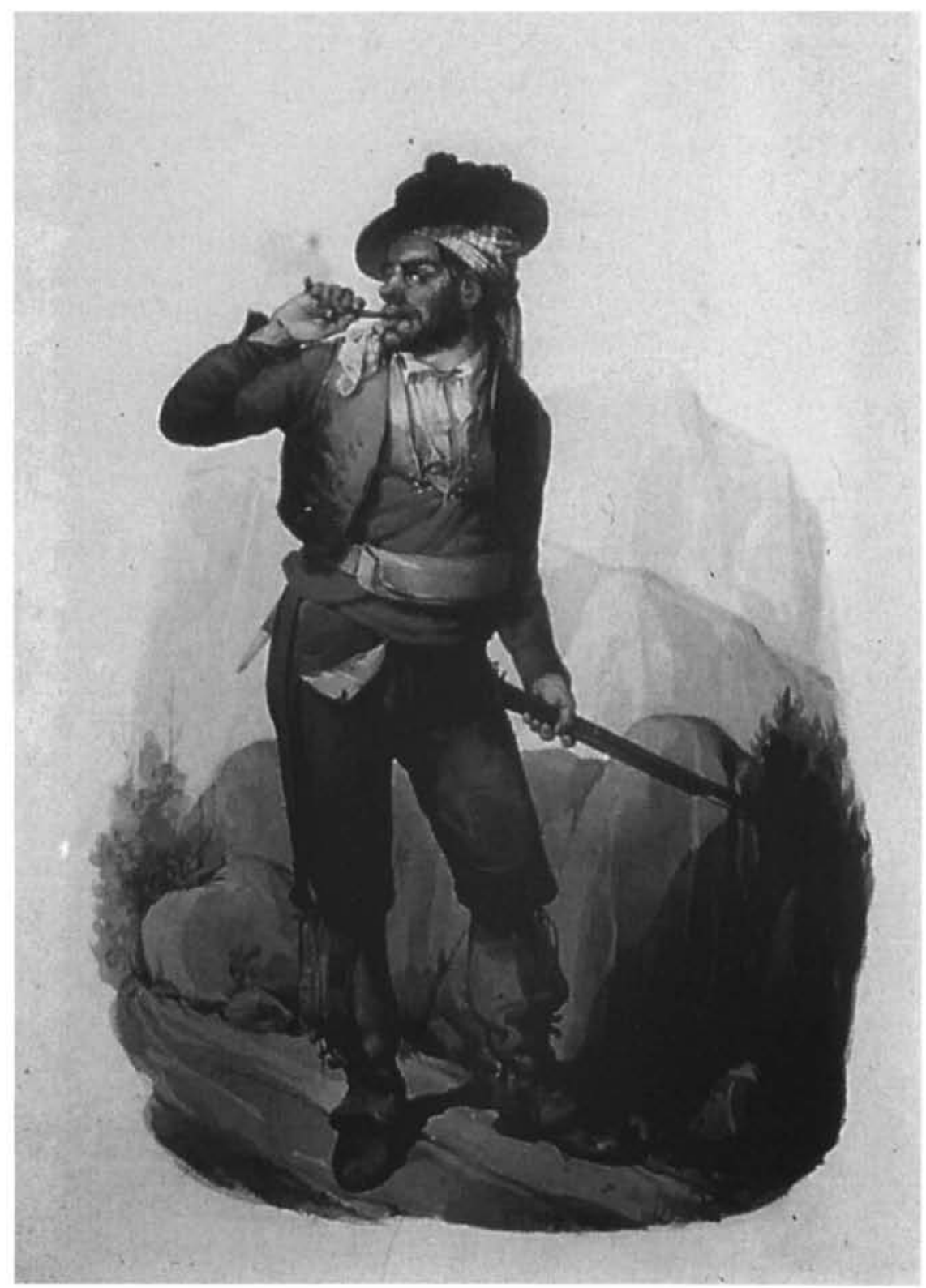

Lám. 3. 


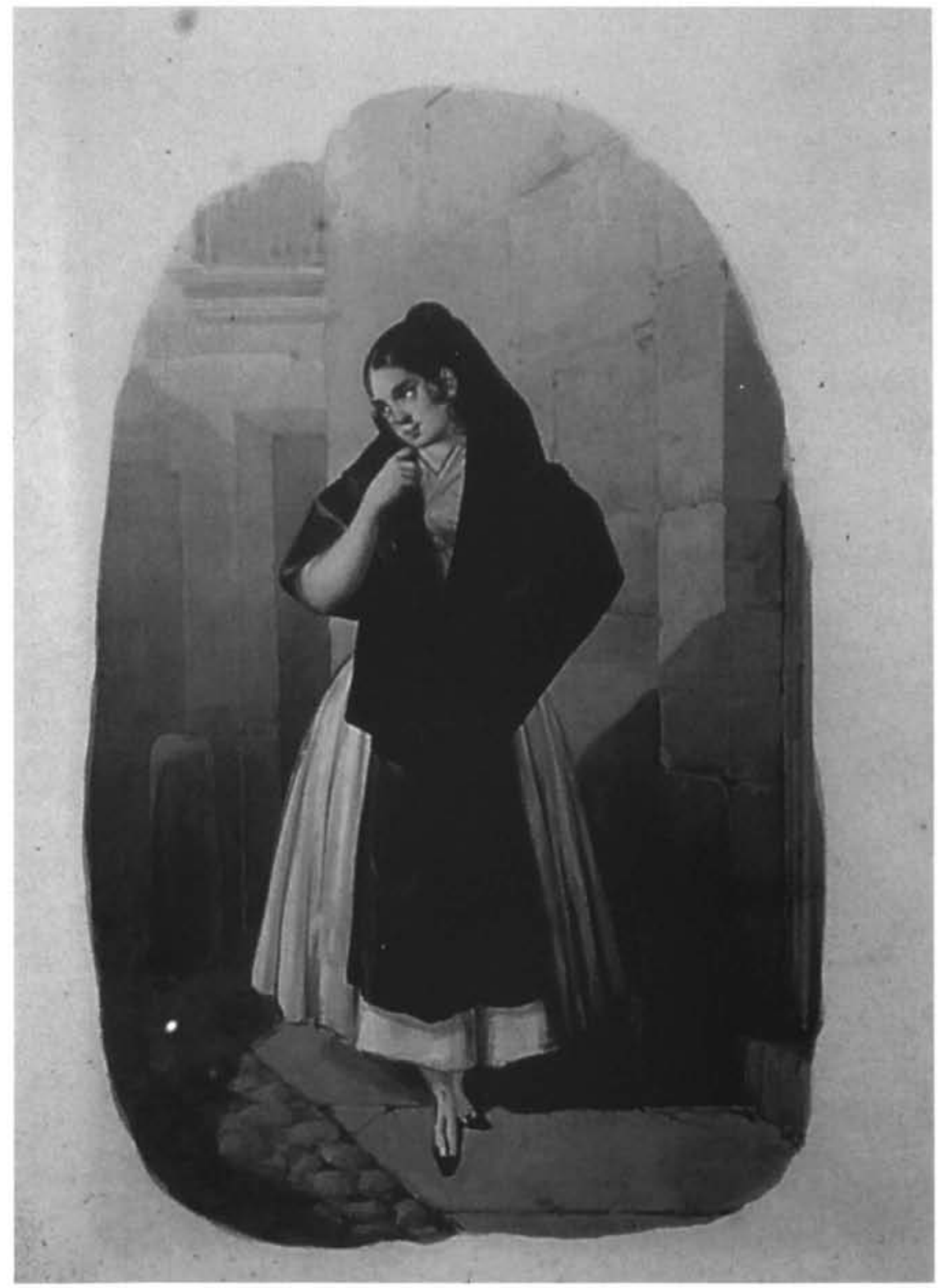

Lám. 4. 